\title{
Consciência fonológica, leitura e compreensão leitora no alemão como língua adicional
}

\author{
Jordana Taís Konrad ${ }^{1}$ \\ Instituto Superior Ivoti, Ivoti, RS, Brasil
}

Aline Lorandi ${ }^{2}$

Programa de Pós-graduação em Linguística Aplicada, Universidade do Vale do Rio dos Sinos,

São Leopoldo, RS, Brasil

Resumo: $O$ presente artigo tem como objetivo promover o desenvolvimento da consciência fonológica de crianças brasileiras aprendizes de língua alemã como língua adicional, estimulado via instrução explícita de aspectos fonético-fonológicos, e verificar se a consciência fonológica pode influenciar no processo de leitura e na compreensão leitora. A pesquisa contou com 30 participantes (entre 10 e 11 anos), 18 do grupo experimental e 12 do controle. A metodologia englobou pré- e pós-teste, envolvendo: tarefas de CF, uma atividade de leitura e compreensão leitora e uma de leitura em voz alta. Na segunda etapa da pesquisa, foram realizados os momentos de instrução explícita em sala de aula, para o trabalho com os sons-alvo da pesquisa. Os resultados revelaram que a instrução explícita proporcionou uma melhora estatisticamente significativa da consciência fonológica dos aprendizes, o que não influenciou, necessariamente, a leitura e compreensão leitora na língua alemã como língua adicional durante o tempo de avaliação da pesquisa.

Palavras-chave: Consciência Fonológica; Compreensão Leitora; Instrução com Foco na Forma; Língua Adicional; Língua Alemã.

Title: In Phonological awareness, Reading, and Reading comprehension in and additional language Abstract: This article discusses the phonological awareness (CF) of learners of German as an additional language and the impact of explicit instruction of phonetic and phonological aspects in reading and reading comprehension of the target language. 30 participants (between 10 and 11 years) took part in the research, 18 in the experimental group and 12 from the control. The methodology included pre and post-test, involving: tasks of $\mathrm{CF}$, an activity of reading and reading comprehension, and reading aloud. In the second stage of the research, the explicit instruction were performed in the classroom, for working with the target sounds of the research. The results revealed that the explicit instruction provided a statistically significant improvement of phonological awareness of the apprentices, which did not necessarily influenced the reading and reading comprehension

\footnotetext{
${ }^{1}$ Mestra (Universidade do Vale do Rio dos Sinos), Instituto Superior Ivoti. Orcid: https://orcid.org/0000-00031014-6188.

E-mail: jordananp@yahoo.com.br.

2 Doutora (Pontifícia Universidade do Rio Grande do Sul), com estágio de pós-doutorado no Birkbeck CollegeUniversity of London, Programa de Pós-graduação em Linguística Aplicada Unisinos. Orcid: https://orcid.org/0000-0002-3886-4950

E-mail: alorandi@unisinos.br.
} 
in German as an additional language, at the time of evaluation of the research.

Keywords: Phonological Awareness; Reading Comprehension; Focus on form instruction; Additional language; German.

\section{Introdução}

Quanto melhor o professor compreender os estágios por que passam os aprendizes durante a aprendizagem de uma língua adicional ${ }^{3}$, maior é a chance de os resultados serem eficientes. Sem dúvida, esse é um dos desafios do professor. Compreender os aspectos que auxiliam na fluência necessária para que se acesse e entenda o conteúdo lido, como, por exemplo, os processos envolvidos na leitura e na compreensão de texto em língua adicional, bem como os processos de decodificação, pode auxiliar o professor na escolha da utilização dos recursos pedagógicos e metodológicos em sala de aula.

Diferentes métodos e diversas abordagens sempre constituíram o ensino de língua adicional. Com o surgimento da abordagem comunicativa e, posteriormente, com o ensino ou a instrução com foco na forma (SPADA, 1997), leva-se em consideração, não somente a forma, mas também o sentido de um determinado aspecto linguístico em contextos autênticos em que os aprendizes devem utilizar a língua de maneira real.

A instrução com foco na forma (doravante IFF), abordada neste trabalho, constitui "qualquer esforço pedagógico que é usado para chamar implícita ou explicitamente a atenção do aprendiz para a forma da língua"“4 (SPADA, 1997, p. 73, tradução nossa). Essa instrução, que pode ser explícita e planejada, é elaborada a partir da decisão tomada pelo professor de língua, que visa a atender a um problema linguístico específico. Assim sendo, há a pré-seleção de formas linguísticas que serão enfocadas na sala de aula, as quais objetivam garantir aos aprendizes oportunidades de exposição e uso das formas-alvo, em meio a um contexto comunicativo de ensino.

O presente estudo, que parte de uma pesquisa realizada no âmbito da Linguística Aplicada e é um recorte da dissertação de Mestrado, nasceu da necessidade de entender por que os alunos aprendizes de alemão como língua adicional sentiam dificuldades na compreensão leitora. Seus comentários levavam a crer que sua dificuldade em pronunciar as palavras levava a dificuldades em apreender seu significado e, consequentemente, entender

\footnotetext{
${ }^{3}$ Neste trabalho, optou-se por utilizar a definição língua adicional quando se faz referência à aprendizagem de outra língua que não seja a língua materna, PB. Essa escolha deve-se ao fato de que, na região em que moram os participantes, os moradores são, em sua grande maioria, descendentes de alemães. Assim, não é incomum ouvir a língua junto de suas famílias. Embora a perspectiva de língua ensinada na escola seja a de língua alemã padrão, entende-se que o fato de os alunos terem a oportunidade de conviver com a língua em seu ambiente familiar a caracteriza como adicional, e não estrangeira, para esses alunos.

${ }^{4}$ Tradução para: "any pedagogical effort which is used to draw the learners attention to language form either implicitly or explicitly".
} 
o que estava sendo lido. Assim, buscou-se investigar se a estimulação da consciência fonológica, sob os pressupostos da Instrução com Foco na Forma (SPADA, 1997; ELLIS, 2001; SPADA; TOMITTA, 2010; MORAES, 2014; DUTRA, 2015) poderia promover uma base para maior acurácia de leitura e melhor compreensão leitora.

O presente artigo discorre sobre esta pesquisa. Nos três primeiros capítulos, apresentam-se aspectos sobre a abordagem da Instrução com Foco na forma, que tem assumido relevância crescente entre os estudos sobre ensino de línguas; o entendimento sobre consciência linguística no qual a pesquisa se ampara, tendo em vista o percurso do grupo de pesquisa das autoras nas pesquisas realizadas ao longo dos últimos anos, a partir do Modelo de Redescrição Representacional; além de reflexões acerca da leitura e da compreensão leitora em língua adicional.

\section{A instrução explícita de aspectos fonético-fonológicos da língua adicional}

Pensar em uma prática pedagógica que integre aspectos fonético-fonológicos ao ensino de outras dimensões da língua adicional é imprescindível. À medida que novos conceitos e abordagens surgem na área de língua adicional, faz-se necessária a reflexão acerca de definições e metodologias mais precisas e a incorporação de uma pedagogia que contribua para que o aprendiz demonstre uma pronúncia mais inteligível. Desse modo, entende-se que o investimento em novos (ou outros) olhares para o ensino de línguas adicionais consiste em possibilidades mais eficazes para que os aprendizes alcancem seus objetivos, seja de comunicação com seu interlocutor, seja de fluência durante leitura, sendo o último o foco deste trabalho.

Uma aula que inclua esses aspectos fonético-fonológicos deve ir muito além da mera repetição mecânica de sons. Tendo em vista a abordagem comunicativa, Celce-Murcia, Brinton e Goodman $(1996,2010)$ propõem cinco estágios para as aulas de pronúncia, a saber: (1) Descrição e análise: os professores fornecem ilustrações orais, visuais e táteis de como o recurso é produzido e onde ocorre para aumentar a consciência do aprendiz; (2) Discriminação auditiva: é praticada usando atividades de escuta focadas com feedback sobre a precisão das percepções do aprendiz; (3) Prática controlada e Feedback: essa fase pode envolver prática com sentenças de pares mínimos contextualizados ou com diálogos curtos ou outros textos com atenção especial para as formas-alvo; (4) Prática guiada e feedback: nesse passo, podem-se incluir exercícios estruturados, mas comunicativos, que ainda permitem ao aprendiz monitorar formas-alvo; (5) Prática comunicativa e feedback: fase em que os aprendizes se envolvem em atividades menos estruturadas, cujo foco está, principalmente, no conteúdo de seus enunciados e apenas secundariamente na forma.

Ao fazer uso sistemático de atividades comunicativas nas aulas, é possível ajudar os aprendizes a praticarem a pronúncia de uma forma que seja transferida para uma situação 
real de comunicação também fora da aula (CELCE-MURCIA, 1983). Acredita-se que um ensino que considere esses passos descritos não somente é mais significativo para o aprendiz, mas também pode garantir maiores chances para que ele atente para as formasalvo, uma vez que estará em contato com tais aspectos linguísticos em um contexto de uso da língua adicional. Dentro da perspectiva da Linguística Aplicada, a aula de pronúncia deve ser de caráter contextualizado e integrado ao desenvolvimento de outras habilidades linguísticas, cuja abordagem apresenta a perspectiva do interagir e significar do aprendiz de língua adicional.

\section{A noção de consciência linguística: modelo de Redescrição Representacional}

Por meio desse tipo de intervenção pedagógica, pode ser estimulado no aprendiz o desenvolvimento da consciência fonológica, quando ele passa a manipular, conscientemente, pequenas estruturas da língua, como os fonemas, por exemplo. Essa área da consciência linguística tem despertado o interesse de linguistas, psicólogos, fonoaudiólogos e educadores, provocando ainda muitas dúvidas que dizem respeito a vários aspectos, relacionados, por exemplo, à idade em que emerge, aos níveis de explicitude e a que tipo de dado pode ser considerado evidência de consciência (NEDSDALE; TUNMER, 1984; KARMILOFF-SMITH, 1992; LORANDI, 2011a; LORANDI; KARMILOFF-SMITH, 2012). Enquanto a maioria dos teóricos, ao falar sobre o desenvolvimento consciência linguística, postula apenas dois níveis de conhecimento implícito e explícito, o modelo Redescrição Representacional (RR) (KARMILOFF-SMITH, 1992, LORANDI, 2011a, LORANDI; KARMILOFFSMITH, 2012) apresenta quatro níveis:

a) Implícito l: a informação está em formato procedimental, representando o insumo como um todo, mas não é analisável em suas partes componentes.

b) Explícito 1 (E1): as representações estão em formato explícito, mas não disponíveis para acesso consciente, nem para relato verbal.

c) Explícito 2 (E2): as representações estão em formato explícito e passam a estar disponíveis para acesso consciente, mas ainda não são verbalizadas.

d) Explícito 3 (E3): as representações estão em formato explícito, são de acesso consciente e estão disponíveis para relato verbal.

Sob esse viés, o conceito de consciência fonológica abordado neste trabalho é o de que consiste na habilidade de tomar as estruturas fonológicas da língua, incluindo fonemas, sílabas, como objetos do pensamento, de modo a, progressivamente, manifestar: sensibilidade aos recursos fonológicos (E1); acesso consciente em tarefas off-line (E2) e relato verbal sobre o conhecimento acessado conscientemente (E3) (LORANDI, 2011a, LORANDI, 2011b, LORANDI; MARQUES, 2016). Desenvolver os diferentes níveis de 
consciência linguística e, mais especificamente, a consciência fonológica (ALVES, 2012b, 2012c) dos aprendizes pode contribuir para o avanço da proficiência do aprendiz em outras habilidades, como será possível constatar na seção abaixo.

\section{Leitura e Compreensão Leitora em Língua Adicional}

A leitura é uma habilidade linguística que recruta o engajamento de consciência e a familiaridade com aspectos da linguagem (PEREIRA, 2012), cujo produto final corresponde à compreensão leitora. Anterior à leitura em si, porém, o aprendiz precisa desenvolver uma sensibilidade linguística para perceber, por exemplo, os sons da língua-alvo, para, então, produzi-los. O terceiro passo dá-se com o início do processo de alfabetização na língua-alvo que, por sinal, apresenta suas especificidades.

O fato é que os aprendizes que começam a ler em língua adicional dispõem de uma base diferente de conhecimento nessa língua da que dispunham a respeito de sua língua materna quando começaram a aprender a ler. A leitura, seja em língua materna, seja em língua adicional, envolve o leitor, o texto, a interação entre leitor e texto (AEBERSOLD; FIELD, 1997), o conhecimento prévio - enciclopédico e linguístico - do leitor (GRABE, 1991; EHLERS, 2006) e o processamento cognitivo da informação linguística em vários níveis: ortográfico, fonológico, sintático e semântico (KODA, 2005).

Portanto, dominar o princípio alfabético (compreender que as letras representam sons) e desenvolver a consciência fonológica (habilidade de atentar para os sons da fala e de manipulá-los intencionalmente, podendo, eventualmente, falar sobre eles) dos aprendizes é considerado indispensável para que se obtenha êxito na leitura (CAPOVILLA, 1999; CAPOVILLA; GUTSCHOW; CAPOVILLA, 2004; SCHERER, 2007; MORAIS, 2013; WOLFF, 2015). De acordo com Capovilla et al. (2004), as instruções de consciência fonológica associadas ao ensino das correspondências entre letras e sons são de grande efeito para a aprendizagem de leitura e escrita.

Anderson (2004) ressalta que um leitor aprende a ler apenas uma vez, pois, quando aprendeu a ler em uma língua, aprende como transferir habilidades que já foram aprendidas para o novo contexto de leitura em uma nova língua. As pesquisas sobre leitura em língua adicional (GRABE, 1991, 2010; AEBERSOLD, FIELD; 1997; KATO, 1999; ZIMMER, 2010) estão ainda muito ancoradas na competência em leitura em língua materna. Por esse motivo, fazse necessária a ampliação de estudos que identifiquem as peculiaridades de cada língua em relação à gama de habilidades envolvidas na leitura, pois cada uma possui características específicas. 


\section{Metodologia de Pesquisa}

\section{Participantes da pesquisa e local de pesquisa}

A pesquisa contou com 30 participantes (entre 10 e 11 anos, sendo a média de idade do grupo experimental é de 10,6 (desvio padrão de 1,7) e do grupo controle 10,6 (desvio padrão de 1,3) aprendizes brasileiros de língua alemã como LA, os quais compunham duas turmas do 5o ano dos Anos Iniciais do Ensino Fundamental I. Possuíam uma hora/aula semanal de língua alemã como LA, sendo essa a única língua adicional ofertada no currículo escolar naquele momento.

Observando o número de alunos em cada turma, optou-se por a turma maior ser o grupo experimental da pesquisa e a turma menor, o grupo controle. 0 grupo experimental foi constituído por 18 participantes, sendo 9 meninas e 9 meninos e recebeu durante um determinado período a instrução explícita de aspectos fonético-fonológicos do alemão. Já o grupo controle era formado por 12 participantes, sendo 9 meninas e 3 meninos e não recebeu a instrução ${ }^{5}$. Detalhes sobre os participantes serão apresentados abaixo.

A pesquisa foi realizada em uma instituição particular, situada em uma cidade da região metropolitana do Rio Grande do Sul e é também o local de trabalho da pesquisadora do estudo, que atua como professora de língua alemã.

\section{Procedimentos de Pesquisa}

A coleta de dados da pesquisa foi dividida em diferentes fases, a saber: realização de teste piloto, entrevista, aplicação dos pré-testes de consciência fonológica, de leitura e compreensão leitora (apresentados a seguir), instrução explícita de determinados aspectos previamente selecionados e aplicação dos pós-testes. Os testes foram gravados em áudio, para que uma análise mais detalhada dos dados fosse possível.

A instrução explícita ocorreu na sala de aula regular, durante aproximadamente 15 minutos, pois a turma tem uma aula semanal de 50 minutos de língua alemã. As atividades de instrução tiveram a duração de três meses (de agosto a novembro), totalizando 12 aulas. Uma semana após o término das aulas com instrução, foi realizada a aplicação do pós-teste. No decorrer das seções, serão explicadas as modificações feitas nas atividades para a

\footnotetext{
${ }^{5}$ Este projeto de pesquisa foi submetido ao Comitê de Ética da Universidade do Vale do Rio dos Sinos, sob o número CAAE 69250117.8.0000.5344, e foi aprovado. Os responsáveis pelos alunos participantes assinaram um Termo de Consentimento Livre e Esclarecido.
} 
realização do pós-teste.

Instrumentos

Teste piloto

Com o intuito de verificar a confiabilidade e a clareza das questões dos testes, foi realizado o estudo piloto com uma população semelhante à do estudo, 32 crianças aprendizes de alemão como língua adicional. Na atividade piloto, os participantes não provinham da escola em que atua a pesquisadora que coletou os dados desta pesquisa. Todos os testes foram aplicados, somente a intervenção não foi possível de ser realizada, visto que não se tinha tempo hábil para tal.

As duas narrativas do teste de compreensão leitora, cuja temática, estrutura e extensão eram semelhantes, foram lidos por 12 juízes, 10 estudantes adultos que estavam no primeiro ou no segundo ano do curso de Letras - Português/Alemão e que apresentam um nível intermediário de conhecimento da língua, além de duas professoras de alemão. A leitura dos diferentes textos foi realizada em semanas diferentes, para que os juízes não se deixassem influenciar e conseguissem discernir as informações dos dois textos.

Atividade de Sondagem

Com o propósito de verificar como estava a desenvoltura em leitura dos aprendizes, logo no início do ano letivo, 16 aprendizes da turma experimental realizaram a leitura de um texto individualmente e em voz alta para a professora-pesquisadora do estudo. A partir dos apontamentos feitos, foi possível perceber que as maiores dificuldades estavam relacionadas aos fonemas e encontros consonantais: /f/ e /v/; /z/ e /ts/; /sp/, /st/ e /s/, uma vez que sua relação com os grafemas correspondentes na língua alvo é diferente da relação que eles conhecem no português. Dessa forma, esses fonemas foram selecionados como os alvos do estudo e da intervenção.

Entrevista com os participantes

Anteriormente à aplicação os testes, uma entrevista semiestrutura individualizada, com algumas questões norteadoras, foi realizada com a amostra-alvo. Tinha-se a intenção de conhecer os participantes, podendo averiguar o contato que eles costumam ter com a 
língua alemã fora da sala de aula, seja por meio de conversas com falantes da variante padrão ou com falantes da língua minoritária da região, chamada de "Hunsrückisch", ou, ainda, de atividades que envolvessem a língua-alvo, como escutar música, olhar vídeos etc.

Dois aspectos chamaram a atenção na entrevista, a saber, o tempo e o contato com a língua. O tempo de contato com a língua alemã da maioria dos participantes foi considerável: $36 \%$ dos participantes têm contato com a língua há 7 anos; $23 \%$ dos participantes há 6 anos; $13 \%$ dos participantes há 5 anos; $16 \%$ dos participantes há 4 anos; 10\% dos participantes há 2 anos. Porém, a partir do Teste t, foi possível apurar que, nessa variável, não houve diferença significativa entres os grupos (GE: Média: 5.56 DP: 1.504; GC: Média: 5.42 DP: 1.832). Além disso, $60 \%$ dos participantes têm pessoas na família que falam uma variação da língua alemã, o "Hunsrückisch". Vale ressaltar que os participantes não têm acesso ao registro escrito, portanto, esse contato se dá, majoritariamente, por meio da escuta da língua. Somente um participante alegou fazer uso da língua para se comunicar com pais e avós, mesmo assim, seus resultados não se diferiram de maneira superior em relação aos dos outros participantes, exceto na leitura e na compreensão no pré-teste, em que obteve os melhores resultados, fato que não se repetiu no pós-teste.

Atividade de Consciência Fonológica da Língua Alemã - Nível do Fonema

Em função da inexistência de testes que verifiquem o nível de consciência fonológica de aprendizes de língua alemã como língua adicional, segundo revisão de literatura realizada, foram elaboradas atividades de consciência fonológica no nível do fonema. Optouse por ter como base o teste CONFIAS (Consciência Fonológica: Instrumento de Avaliação Sequencial), que é um instrumento que tem como objetivo avaliar a consciência fonológica de forma abrangente e sequencial, no nível da sílaba e do fonema, para falantes de português como língua materna (MOOJEN, 2011).

As atividades compreenderam: produção de palavra que inicia com o fonema dado (6 itens); identificação de fonema inicial ( 9 itens); identificação de fonema medial (fonema inicial de sílaba medial ( 9 itens); julgamento de fonema medial (9 itens); julgamento de aceitabilidade e produção de palavras com fonemas dados (18 itens). A elaboração das atividades teve amparo teórico no Modelo de Redescrição Representacional, que aborda diferentes níveis de explicitude em que o conhecimento é redescrito, partindo de um nível procedimental até o último nível de consciência, a verbalização.

Anteriormente à aplicação do teste, realizou-se a averiguação do conhecimento lexical do aprendiz na língua-alvo, com o intuito de assegurar que o vocabulário não seria um fator de dificuldade para os testes. Primeiramente, imagens foram mostradas, e o participante as nomeava em alemão. Em seguida, a pesquisadora dizia uma palavra em português, e o participante pegava a imagem correspondente e retomava a palavra em 
alemão. Os participantes também eram instigados a pensar em alguma frase em alemão para empregar a palavra. Vale reforçar que as palavras foram retiradas do material trabalhado com os alunos, apresentando o nível linguístico esperado para aquela faixa etária.

Com relação ao teste de $\mathrm{CF}$, a pontuação máxima, no total de questões, corresponde a 51 pontos. A primeira questão de cada grupo de atividades não foi avaliada, por servir de treino. Além disso, outras questões distratoras foram inseridas para que os alvos testados não ficassem evidentes, inibindo um possível monitoramento. Como se trata de um teste muito específico, para a realização do pós-teste não foram feitas alterações, contudo, a ordem dos itens foi modificada.

Atividade de Leitura Silenciosa e Compreensão Leitora

Para avaliar a compreensão leitora dos participantes, utilizou-se como base o teste Cloze (SANTOS; BORUCHOVITCH; OLIVEIRA, 2009), que envolve a habilidade do leitor em estabelecer relações entre os elementos do texto e a sua capacidade de desenvolver associações apropriadas entre o conhecimento prévio e a informação impressa.

Para pré- e pós teste, narrativas distintas foram utilizadas, as quais continham 250 palavras e abordaram assuntos familiares para os participantes, como: família, amigos, animais e brincadeiras. As duas narrativas compunham parte do projeto de instrução com foco na forma desenvolvido para este estudo. O processo de lacunamento foi observado minuciosamente, para que o participante tivesse de fazer uso das informações anteriores do texto para marcar a resposta esperada. O critério de escolha das alternativas foi: a) uma palavra que apresentasse traços fonológicos semelhantes à palavra-alvo; b) uma palavra que fosse semanticamente possível dentro daquele contexto e c) resposta esperada, dispostas aleatoriamente, como no exemplo a seguir: a) wir [vi:r], b) viele [fi:le],c) vier [fi:r]. Embora as narrativas tenham sido diferentes no pré- e no pós- teste, mantiveram-se as palavras com os sons-alvo.

Primeiramente, o aprendiz tinha de ler silenciosamente o texto e, no segundo momento, marcar a alternativa que considerava adequada para cada lacuna. Em seguida, com o intuito de verificar a habilidade de compreensão global, o aprendiz era convidado a assinalar, dentre 5 alternativas, aquela que julgasse apresentar um título adequado para a narrativa.

Atividade de Leitura em Voz Alta: Acurácia, Tempo e Compreensão

Para avaliar a acurácia, o tempo e a compreensão leitora, foram produzidos dois 
textos, um para cada fase da pesquisa. Para a elaboração dos textos, observou-se que a temática fosse conhecida pelos aprendizes e que a extensão permanecesse a mesma, como número de 150 palavras ${ }^{6}$. A leitura em voz alta do participante foi gravada, com o intuito de efetuar-se uma análise mais minuciosa posteriormente. Em seguida, foram realizadas oralmente 11 perguntas em alemão sobre o texto. Sem consultar o texto, o participante tinha de respondê-las em alemão ou português, uma vez que se tinha como objetivo verificar a compreensão leitora. A partir dessa leitura em voz alta, era feita a checagem da compreensão.

Aulas com Instrução Explícita de Aspectos Fonético-Fonológicos da Língua Alemã

Somente o grupo experimental recebeu instrução explícita acerca dos aspectos fonético-fonológicos da língua-alvo selecionados (os fonemas /v/, /f/, /z/, /tz/, /s/ e os encontros consonantais $/ \mathrm{sp} /$, $/ \mathrm{ft} /$.). As sessões foram realizadas semanalmente no período de aula regular de língua alemã, totalizando 12 aulas, sendo que a instrução teve a duração média de 15 minutos em cada aula.

As atividades desenvolvidas durante a instrução explícita estavam interligadas ao assunto previsto para aquele período, de forma que estivessem integradas ao que já estava sendo trabalhado nos projetos na escola. Desse modo, conforme abordado anteriormente, por se tratar de um ensino comunicativo de pronúncia, na sala de aula de língua adicional, foram trabalhados os cinco estágios da autora Celce-Murcia, Brinton e Goodman (1996, 2010).

As atividades das aulas foram divididas em: atividades individuais, em atividades com trocas colaborativas ${ }^{7}$ em duplas, em pequenos grupos e em atividades para discussão no grande grupo. Para as aulas, a motivação dos aprendizes foi instigada e foram exercitados o foco da atenção e a prática de determinados aspectos fonético-fonológicos. Para tanto, os aprendizes acessaram o mesmo conteúdo de diferentes formas, seja por meio de materiais visuais e auditivos, como em vídeos, músicas, diálogos, pequenos textos, trava-línguas, atividades escritas, leituras, seja na interação com os colegas nas atividades em individuais, em dupla ou em grupos.

Ocorreram momentos em que a turma foi convidada a explicitar o seu pensamento a respeito dos aspectos já mencionados. A etapa comunicativa ficou para o final das instruções explícitas, tendo em vista que os participantes precisavam inicialmente construir conhecimento, pois se encontram em um nível inicial de proficiência na língua adicional.

\footnotetext{
${ }^{6}$ Juízes professores de alemão avaliaram os textos para averiguar sua similaridade e adequabilidade em função do objetivo de seu uso na pesquisa.

7 Tarefas com trocas colaborativas são aqui compreendidas como aquelas em que os participantes necessariamente necessitam de um colega para a resolução da atividade na LA (SWAIN, 2000).
} 
Celce-Murcia, Brintos e Goodman (1996) consideram importante que o professor avance conforme o ritmo dos aprendizes e que, se necessário for, alguns passos sejam reforçados para que as dificuldades sejam trabalhadas. Por esse motivo, é possível ver nas aulas a repetição dos passos 3 e 4. Para que os participantes conseguissem acompanhar e, ao final do trabalho, apreciar um panorama geral do que fora trabalhado nas aulas, organizou-se um pequeno livro com as atividades desenvolvidas no período.

Em momentos de interação entre os participantes, como em atividades dirigidas em duplas, em diálogos ou jogos, a pesquisadora procurou registrar algumas contribuições. Conforme Slobin (1980), os aspectos de consciência linguística podem ser observados por meio de: (1) autocorreções e reformulação no curso da fala em andamento; (2) comentários sobre o discurso dos outros (pronúncia, dialeto, idioma, significado, adequação, estilo, volume, etc.); (3) perguntas explícitas sobre a fala e a língua; (4) comentários sobre a própria fala/linguagem; (5) respostas a perguntas diretas sobre a língua; e ainda, (6) comentários sobre a língua. Esse tipo de manifestação, assim como os pressupostos do modelo RR, guiaram a percepção da pesquisadora para acompanhar comentários dos alunos que pudessem evidenciar consciência linguística durante esses momentos de interação e de troca em sala de aula.

A verificação dos efeitos da instrução foi medida com a aplicação do pós-teste que ocorreu uma semana após o término da instrução explícita.

\section{Resultados quantitativos e discussão}

Com base nos resultados do Teste t de Student, pode-se verificar e se há diferença significativa nas distintas etapas de coleta de dados e entre os grupos (GE e GC), tendo em vista a instrução realizada com o GC. Em razão de os grupos serem dissimilares em termos de quantidade de alunos, os escores de cada item dos testes foram computados estatisticamente, obtendo-se as médias e o desvio padrão de cada grupo.

Comparação entre os resultados do pré-teste e do pós-teste

Constatou-se, por meio dos escores do Teste $t$, no pré-teste, na atividade de consciência fonológica, que existiam diferenças entre o grupo experimental e controle, pois a média do grupo controle era superior à do grupo experimental. Por esse motivo, passou-se a objetivar o igual ou melhor desempenho do GE em comparação ao GC no pós-teste. 
Tabela 1 - Resultados estatísticos do pré-teste

\begin{tabular}{|c|c|c|c|c|c|c|}
\hline \multicolumn{7}{|c|}{ PRÉ-TESTE } \\
\hline & \multicolumn{2}{|c|}{ Grupo experimental } & \multicolumn{2}{|c|}{ Grupo Controle } & \multicolumn{2}{|c|}{ GE $X$ GC } \\
\hline & Média & $\begin{array}{l}\text { Erro padrão da } \\
\text { média }\end{array}$ & Média & $\begin{array}{c}\text { Erro padrão da } \\
\text { média }\end{array}$ & Valor de $t$ & Significância \\
\hline $\begin{array}{l}\text { Consciência } \\
\text { fonológica }\end{array}$ & 34.17 & 1.364 & 38.83 & 1.006 & -2.679 & .021 \\
\hline $\begin{array}{c}\text { Leitura e } \\
\text { compreensão }\end{array}$ & 8.75 & .993 & 9.33 & .595 & -.434 & .673 \\
\hline Tempo & 2.5300 & .20740 & 2.5200 & .12254 & .038 & .970 \\
\hline Questões & 4.75 & .799 & 4.58 & .701 & .140 & .891 \\
\hline
\end{tabular}

Fonte: Konrad (2018, p. 76).

Como resultado da intervenção pedagógica baseada na instrução com foco na forma explícita, que ocorreu durante o segundo semestre de 2017, o GE foi se assemelhando ao GC no que diz respeito à tomada de consciência linguística de alguns aspectos da língua-alvo. $A$ Tabela 2 mostra que, na comparação entre os grupos, no pós-teste, a diferença entre eles não foi mais estatisticamente significativa, uma vez que ambos os grupos obtiveram médias similares, mostrando, assim, certa homogeneidade entre eles.

Tabela 2 - Resultados estatísticos do pós-teste

\begin{tabular}{|c|c|c|c|c|c|c|}
\hline \multicolumn{7}{|c|}{ PÓS-TESTE } \\
\hline & \multicolumn{2}{|c|}{ Grupo experimental } & \multicolumn{2}{|c|}{ Grupo Controle } & \multicolumn{2}{|c|}{ GE $X$ GC } \\
\hline & Média & $\begin{array}{l}\text { Erro padrão da } \\
\text { média }\end{array}$ & Média & $\begin{array}{l}\text { Erro padrão da } \\
\text { média }\end{array}$ & Valor de $t$ & Significância \\
\hline $\begin{array}{l}\text { Consciência } \\
\text { fonológica }\end{array}$ & $39.08^{8}$ & .821 & 39.75 & 1.399 & -.498 & .628 \\
\hline $\begin{array}{c}\text { Leitura e } \\
\text { compreensão }\end{array}$ & 10.17 & .757 & 9.92 & .609 & .248 & .809 \\
\hline Tempo & 2.2658 & .14194 & 2.2700 & .11424 & -.019 & .985 \\
\hline Questões & 5.08 & .621 & 4.25 & .653 & .969 & .353 \\
\hline
\end{tabular}

Fonte: Konrad (2018, p. 77).

Em função de o GC ter apresentado altos escores na atividade de consciência fonológica, já no pré-teste, o GE conseguiu, no mínimo, equiparar-se ao GC, o que, portanto, mostra a evolução do GE, fato que será elucidado detalhadamente nas seções a seguir.

Comparação dos resultados do pré- teste e do pós-teste em cada grupo (GE e GE)

Embora a amostra da população estudada seja pequena, relacionando os dados do

\footnotetext{
${ }^{8}$ Ao realizar a comparação entre as duas amostras de pesquisa por meio do Teste $t$, elas tiveram de ser equiparadas quanto ao número de participantes, N:12. Por esse motivo, as médias apresentam pequenas diferenças, mas que não comprometem os resultados.
} 
pré-teste com os do pós-teste, é possível tecer algumas considerações relevantes. É evidente que generalizações devem ser sempre cuidadosas e, em função disso, apontam-se apenas algumas tendências que podem ser recorrentes na aula de alemão e que podem auxiliar o professor a repensar suas futuras práticas pedagógicas.

Para o grupo experimental, que recebeu, em 12 aulas, instrução explícita com foco em aspectos fonético-fonológicos do alemão, no pós-teste, o valor de $p$ no Teste t revelou-se significativo estatisticamente em quatro atividades: na de consciência fonológica, no nível do fonema, na leitura silenciosa e compreensão leitora, na leitura realizada com acurácia e no tempo de leitura (ver tabela 3). Em vista disso, percebe-se que a intervenção pedagógica, com predomínio da instrução explícita, parece ter produzido efeitos positivos sobre as formas-alvo em estudo.

Tabela 3 - Resultados estatísticos do grupo experimental

\begin{tabular}{|c|c|c|c|c|c|c|}
\hline \multicolumn{7}{|c|}{ GRUPO EXPERIMENTAL } \\
\hline & \multicolumn{2}{|c|}{ Pré-teste } & \multicolumn{2}{|c|}{ Pós- teste } & \multicolumn{2}{|c|}{ Pré-teste X Pós-teste } \\
\hline & Média & $\begin{array}{c}\text { Erro padrão da } \\
\text { média }\end{array}$ & Média & $\begin{array}{c}\text { Erro padrão da } \\
\text { média }\end{array}$ & Valor de $t$ & Significância \\
\hline $\begin{array}{l}\text { Consciência } \\
\text { fonológica }\end{array}$ & 35.11 & 1.185 & 39.39 & .687 & -5.193 & .000 \\
\hline $\begin{array}{c}\text { Leitura e } \\
\text { compreensão }\end{array}$ & 8.11 & .816 & 9.94 & .639 & -2.580 & .019 \\
\hline Tempo & 2.4583 & .15954 & 2.1978 & .12601 & 2.417 & 0.27 \\
\hline Questões & 4.78 & .689 & 5.11 & .457 & -.753 & .462 \\
\hline
\end{tabular}

Fonte: Konrad (2018, p. 78).

Se a aprendizagem da língua adicional é ocasionada primordialmente por aquilo em que os aprendizes prestam atenção e percebem no insumo da língua-alvo (SCHMIDT, 2001), pode-se concluir que a intervenção pedagógica deste estudo, que incluiu diferentes atividades, contribuiu efetivamente para que os aprendizes exercitassem, em especial, as formas-alvo. Em outras palavras, após a intervenção explícita, o resultado do primeiro teste sugere que o resultado para as formas-alvo não é aleatório, mas possivelmente fruto dessa intervenção, uma vez que houve o aumento da frequência no insumo fornecido aos participantes. Isso parece ficar mais evidente em função de o crescimento em consciência fonológica ter sido maior que nas demais variáveis.

Resultado do direcionamento da atenção consciente do aprendiz a determinados aspectos linguísticos, no caso, aspectos fonético-fonológicos, durante o insumo em língua adicional, foram os escores positivos do grupo experimental em relação aos do grupo controle, pois os aprendizes do GE foram expostos a diferentes materiais, concentrando-se tanto na forma quanto em aspectos semânticos do idioma. Pode-se, assim, afirmar que este trabalho corrobora os estudos já mencionados na área de língua adicional (SPADA, 1997; NORRIS; ORTEGA, 2000; SPADA; TOMITA, 2010; SPADA; LIGHTBOWN, 2008; DUTRA, 2015; MORAES, 2014), que têm indicado resultados favoráveis da instrução explícita na 
aprendizagem de língua adicional, posto que contribui para uma aprendizagem efetiva de determinados aspectos linguísticos da língua-alvo.

No que diz respeito à compreensão leitora, à acurácia e ao tempo de leitura, os dados mostram que também houve um aumento na média, apontando para diferenças significativas estatisticamente entre o pré- e o pós-teste no GE. Em consequência disso, partiu-se da hipótese de que esses resultados estavam atrelados à melhora da consciência fonológica na língua alemã. No entanto, essa relação entre consciência fonológica e leitura na língua, que acontece na língua materna (CAPOVILLA, 1999; CAPOVILLA; GUTSCHOW; CAPOVILLA, 2004; SCHERER, 2007; WOLFF, 2015) não necessariamente acontece da mesma forma na língua adicional. Verificar se os dados de consciência fonológica iriam se correlacionar positivamente com os de compreensão leitora, acurácia e tempo de leitura, foi o próximo passo e, para tanto, realizou-se a correlação do coeficiente de Pearson, sendo o valor de $r$.097 para a compreensão leitora, .268 para acurácia e .-086 para o tempo de leitura. A hipótese foi negada, e pôde-se constatar que essa melhora parece não ser vinculada ao aumento dos resultados relativos à consciência fonológica. Todavia, o único aspecto que difere as duas amostras é, justamente, a instrução explícita com foco na forma trabalhada somente com o GE. Possivelmente, se o número de participantes fosse maior, os resultados estatísticos poderiam ter sido outros.

Com relação às questões respondidas posteriormente à leitura em voz alta, não houve alteração significativa nos dados. Esses resultados podem ter sido influenciados pelo tipo de atividade realizada posteriormente à leitura, que compreendia responder a perguntas feitas oralmente pela pesquisadora, sem a possibilidade de nova consulta ao texto. Naquele momento, a compreensão detalhada do texto requerida, eventualmente, não estava ao alcance para alguns dos aprendizes. Ademais, os dois textos consistiam em narrativas que exigiam uma determinada abstração do leitor, apesar de os assuntos fazerem parte do entorno pessoal dos aprendizes. Outro aspecto importante a ser considerado é que, além da habilidade de compreender o que estava sendo lido, os aprendizes deviam observar a leitura acurada, fato que pode ter dificultado a retenção das informações na memória. Em outras palavras, em função de os alunos terem se concentrado na acurácia para a leitura exata das palavras, bem como no tempo de leitura (sua leitura estava sendo cronometrada), talvez o foco da atenção não tenha sido no conteúdo do texto, o que, por sua vez, pode ter dificultado sua apreensão para posterior compreensão. Um estudo realizado por Bernhardt (1983), também com estudantes de língua alemã, mostrou que a leitura silenciosa favorece a compreensão, enquanto a leitura em voz alta não promove os mesmos resultados, independentemente do conhecimento gramatical dos alunos. 0 impacto da leitura em voz alta ou silenciosa sobre a compreensão, contudo, não é consenso. Uma pesquisa realizada por Hale et al. (2007), com alunos do Ensino Médio e do Fundamental ${ }^{9}$, lendo em sua língua materna, tanto em voz alta quanto em silêncio, mostrou

\footnotetext{
${ }^{9}$ Secondary and elementary students.
} 
que a compreensão de leitura foi significativamente melhor quando a leitura foi feita em voz. Esse parece ser um tema ainda a ser mais explorado por estudos futuros, visto que a literatura não é vasta, de modo especial levando-se em consideração diferenças entre primeira e segunda línguas.

Considerando-se o grupo controle, durante os dois momentos da pesquisa, conforme tabela 4 (ver abaixo), os resultados foram estatisticamente significativos somente na acurácia e no tempo de leitura. Esses dois aspectos podem ter sido influenciados em função do contato com a língua que os aprendizes tiveram durante os meses da aplicação do teste, ou seja, pode ter sido efeito de aprendizagem e avanço na proficiência na língua. Já com relação à consciência fonológica e leitura e compreensão leitora, diferentemente do $\mathrm{GE}$, o GC não obteve maiores índices, sendo que, no pré-teste, na atividade de consciência fonológica, havia alcançado escores mais altos.

Tabela 4 - Resultados estatísticos do grupo controle

\begin{tabular}{cccccccc}
\hline \multicolumn{7}{c}{ GRUPO CONTROLE } \\
\hline & Média & $\begin{array}{c}\text { Eré-teste } \\
\text { Erro padrão da } \\
\text { média }\end{array}$ & Média & $\begin{array}{c}\text { Eós- teste } \\
\text { madrão da } \\
\text { média }\end{array}$ & Valor de t & Significância \\
\hline $\begin{array}{c}\text { Consciência } \\
\text { fonológica } \\
\text { Leitura e }\end{array}$ & 38.83 & 1.006 & 39.75 & 1.399 & $\mathbf{- . 8 8 7}$ & $\mathbf{. 3 9 4}$ \\
$\begin{array}{c}\text { compreensão } \\
\text { Acurácia }\end{array}$ & 9.33 & .595 & 9.92 & .609 & $\mathbf{- 1 . 7 3 5}$ & $\mathbf{. 1 1 1}$ \\
$\begin{array}{c}\text { Tempo } \\
\text { Questões }\end{array}$ & 111.42 & 3.528 & 124.75 & 2.465 & $\mathbf{- 7 . 2 3 2}$ & $\mathbf{. 0 0 0}$ \\
& 2.5200 & .12254 & 2.2700 & .11424 & $\mathbf{3 . 0 7 4}$ & $\mathbf{. 0 1 1}$ \\
& 4.58 & .701 & 4.25 & .653 & $\mathbf{. 5 7 3}$ & $\mathbf{. 5 7 8}$ \\
\hline
\end{tabular}

Fonte: Konrad (2018, p. 81).

Em síntese, a partir da explanação dos dados, é perceptível a necessidade do professor de língua adicional de reservar momentos específicos em aula para oportunizar atividades que priorizem não apenas o significado, mas, de certa forma, abordem aspectos fonético-fonológicos das línguas L1 e língua adicional. Dessa forma, é possível estabelecer diferenças e semelhanças, levando os aprendizes a direcionarem sua atenção de forma consciente para os alvos e, por conseguinte, compreender e fazer uso desses conhecimentos em contextos diversificados. A instrução explícita com foco na forma de aspectos fonéticofonológicos pode contemplar esses e ainda outros aspectos da língua-alvo.

Outro aspecto importante é que ler em voz alta é um grande desafio para muitos aprendizes. A atividade de realizar a leitura em voz alta apenas uma vez exigiu do aprendiz o direcionamento de sua atenção para a pronúncia acurada. Por isso, alguns participantes acabaram ficando no nível da decodificação, o que, aparentemente, exigiu um nível de monitoramento bastante alto dos aprendizes. O participante PE10 chegou a relatar: "Eu não consigo prestar atenção no texto quando leio em voz alta, preciso ler baixinho pra mim". E aqui também se faz necessária uma ponderação a respeito da prática da leitura em voz em sala de aula. Por vezes, essa habilidade é pouca exercitada durante as aulas, em função do 
grande número de aprendizes, ou, inclusive, pela própria resistência por parte de alguns aprendizes em realizar essa prática, fato esse que precisa ser repensado, visto que pode influenciar o êxito na leitura, de modo especial em termos de acurácia e fluidez.

A partir da pesquisa bibliográfica, foi possível perceber também que, na língua adicional, vários outros fatores relevantes influenciam a leitura e a compreensão leitora, como constata Gombert (1992), quando traz a hierarquia no desenvolvimento da compreensão leitora. Após a compreensão do que significa ler, esse autor destaca primeiro o conhecimento lexical, pois a riqueza do vocabulário alimenta o processo de inferências linguísticas. A autora Zimmer (2010b) também reforça a importância da consistência e da frequência do léxico e Grabe (2010) enfatiza ainda o reconhecimento de um amplo vocabulário (GRABE, 2010) para que esse processo de leitura seja efetivo. Esses aspectos foram reforçados nas atividades guiadas durante a instrução explícita.

Com essas noções constituídas, segundo Gombert (1992), as habilidades de consciência semântica, seguida pela consciência fonológica e, por fim, pela consciência sintática são mobilizadas para que a compreensão leitora ocorra. Essas habilidades precisam, por sua vez, ser muito mais enfatizadas em sala de aula para que os aprendizes percebam o domínio da língua e, consequentemente, consigam realizar a leitura e a tentar compreender o texto. O próximo passo, na percepção do autor, é o trabalho com a consciência fonológica.

Para que os processos de decodificação e de acesso lexical (processos ao nível das palavras) possam ocorrer, faz-se necessário que o leitor desenvolva as habilidades de compreensão das palavras em língua adicional, a fim de que possa não apenas conhecer as palavras do texto, mas também acessar significados contextualmente relevantes para essas palavras, relacionando-as a outros conceitos exigidos pelo contexto. Desse modo, as palavras mais frequentes na língua são reconhecidas mais rapidamente pelos leitores, ao passo que as menos frequentes serão processadas com maior dificuldade. Tal frequência aponta para o conhecimento que o leitor possui de determinado repertório lexical e fonético-fonológico (JERÔNIMO, 2012). A velocidade e precisão de leitura dependem também, segundo Kato (1999), de a palavra estar registrada no léxico visual pela frequência com que o leitor já foi exposto a ela e por ter a ela acoplado o seu sentido.

Seja no nível fonológico, no morfossintático, no semântico ou no pragmático, o uso das habilidades de leitura em primeira língua para compreender a língua adicional (ZIMMER, 2008) não é suficiente para se alcançar um nível de compreensão leitora mais avançado. Além disso, em função do nível de proficiência do leitor na L1 desempenhar um importante papel no desenvolvimento da habilidade de leitura em língua adicional (PORFIRIO, 2014), seria válido, em pesquisas futuras, realizar um teste de QI e um teste de leitura também na L1 para que a comparação entre as línguas fosse possível, esclarecendo, assim, os fenômenos envolvidos na leitura na língua adicional. O presente trabalho alcançou resultados que contribuem para a investigação de aspectos linguísticos na relação entre consciência fonológica, leitura e compreensão leitura na língua alemã como língua adicional. 


\section{Resultados Qualitativos e discussão}

Durante as aulas com a intervenção pedagógica, os participantes foram estimulados a refletirem sobre alguns aspectos linguísticos em específico e, nas interações com os colegas, podiam fazer comentários sobre aspectos considerados relevantes. Destacam-se aqui comentários que foram identificados como ilustração dos diversos níveis de redescrição representacional.

\section{Nível Explícito 1}

Em alguns momentos, foram observadas contribuições de nível E1. Durante a instrução 4, os aprendizes foram desafiados a ler, produzir os fonemas-alvo para que conseguissem, em seguida, expressar a sua opinião a respeito de um determinado enunciado, como por exemplo, "In der Sporthalle Fußball spielen? Schön!" (No ginásio jogar futebol? Legal!). Durante a prática guiada, que foi desenvolvida em duplas, um dos participantes fez o seguinte comentário:

(1) "O colega ${ }^{10}$ fica falando Fubball!" (FuBball ['fu:sbal]: futebol) (Participante: PE 15)

A partir da pronúncia do colega, o aprendiz PE15 evidenciou uma sensibilidade linguística para a produção da fricativa alveolar desvozeada /s/ em posição de coda silábica. A palavra "Fußball" é, com frequência, lida incorretamente em detrimento da inexistência do grafema " $\beta$ " na língua materna dos aprendizes do estudo.

\section{Nível Explícito 2}

Durante a instrução 2, na atividade de discriminação auditiva, os aprendizes tinham de ouvir a produção de um vocábulo e assinalar o fonema ouvido. A partir do comentário sobre a pronúncia, o participante PE12 deixa evidente que a produção de " $\beta$ " é /s/, pois manipula intencionalmente uma pequena estrutura da língua, evidenciando acesso consciente ao conhecimento fonológico da língua, produzindo o resultado para "Fub", a partir de uma tarefa offline.

(2) "Lehrerin (Professora), o 8 (eszet) tem som de /s/ né, senão ficaria fub". (Fuß [fus] Participante: PE 12)

\footnotetext{
${ }^{10}$ Optou-se em usar a palavra "colega” para fazer referência à pessoa de quem se estava falando para garantir o sigilo dos participantes.
} 
Assim como na contribuição de PE12, a produção da fricativa alveolar desvozeada /s/, representada pelo grafema " $\beta$ " é, com frequência, realizada como uma oclusiva /b/ devido à inexistência desse grafema na língua materna e da semelhança com o grafema "B".

Vale destacar que, nas atividades de CF, no item de julgamento de aceitabilidade e produção, no pré-teste, o GE teve um escore de acertos de 21 respostas em nível E2 e, no pós-teste, 53 respostas, o que revela que o grupo teve índices mais altos, pois o crescimento é de mais de $50 \%$.

Nível Explícito 3

Ainda na atividade de $\mathrm{CF}$, no item de julgamento de aceitabilidade e produção, no pós-teste, vale destacar que $88 \%$ dos participantes do GE passaram a identificar o erro e a produzir corretamente a palavra-alvo, o que revela que os participantes passaram a ter maior consciência para determinados sons da língua-alvo, a ponto de, inclusive, conseguir produzi-los corretamente. Também houve a verbalização do conhecimento, como por exemplo, no item F5.17, „X $\mathrm{X}^{11}$ ist meine Stadt [estat]“ ( $\mathrm{X}$ é minha cidade.), a pronúncia deveria ser: [Jtat]. O participante PE2 identificou o erro, produziu a palavra-alvo e elucidou:

(3) "X não é um estado, é uma cidade."

O participante inferiu que a palavra pronunciada com a inserção da vogal epentética poderia comprometer a compreensão do que, de fato, a palavra " $X$ " significa uma cidade e não um estado. Ao externar a sua compreensão trazendo a noção de estado e cidade, é perceptível que o participante se encontra em nível mais avançado de consciência linguística, o nível explícito 3.

\section{Considerações Finais}

O presente trabalho buscou elucidar, de forma sucinta, os resultados encontrados no trabalho de consciência fonológica via instrução explícita com foco na forma e a sua influência no processo de leitura e compreensão leitora em língua adicional. Os resultados obtidos na pesquisa podem contribuir para a subárea da Instrução com Foco na Forma e colaborar com o entendimento do desenvolvimento da consciência fonológica na língua adicional e dos níveis E1, E2, E3, bem como com a compreensão de aspectos específicos relacionados à leitura e à compreensão leitora na língua adicional.

A partir da formação dos grupos de pesquisa, sendo a turma maior o GE e a menor o

\footnotetext{
${ }^{11}$ Para manter sigilo, optou-se em utilizar a letra $\mathrm{X}$ para referir a cidade mencionada pelo aluno, de modo a manter os cuidados éticos da pesquisa.
} 
GC, foi possível tecer algumas considerações importantes sobre a população estudada. Como o GC apresentou ligeiramente mais altos já no pré-teste, passou-se a ter o objetivo de equiparar os grupos ou obter resultados ainda melhores. A partir do contato semanal com as turmas, foi possível perceber que os aprendizes do GC estavam mais atentos a qualquer aspecto linguístico durante as aulas, pois questionavam os fenômenos e faziam comparações entre línguas. Isso pode sugerir o porquê de o grupo de controle ter apresentado resultados melhores do pré teste. Entende-se que a diferença entre os grupos pode ser entendida como umas das limitações, contudo o resultado do pós teste ressalta a importância do trabalho voltado para a consciência de aspectos linguísticos em sala de aula, a partir de instrução explícita. Vale lembrar, ainda, que, em função de a amostra ser pequena, não é possível fazer afirmações que possam ser generalizadas a qualquer grupo de aprendizes de alemão como LA. Apontam-se aqui tendências que podem ser recorrentes na aula de alemão com LA.

Os dados evidenciaram que houve diferenças de desempenho entre o grupo experimental e o grupo controle em relação ao nível de consciência fonológica, à leitura e à compreensão leitora. No pós-teste, na atividade de consciência fonológica, o GE apresentou uma média muito próxima ao GC o que evidencia o crescimento significativo do GE. Na leitura silenciosa, 15 participantes ( $\mathrm{N}: 18$ ) obtiveram resultado igual ou melhor. Além disso, todos os participantes do GE aumentaram o número de palavras lidas com exatidão e 12 diminuíram seu tempo de leitura. Assim sendo, a presente pesquisa pode instigar a reflexão sobre o trabalho dos aspectos fonético-fonológicos e a elaboração de novas estratégias de ensino que favoreçam o aprendizado da língua alemã via estimulação da consciência fonológica, uma vez que ela foi benéfica à aprendizagem dos sons-alvo.

Há inúmeros fatores que interferem no processo de aprendizagem de uma língua adicional e enfatizou-se neste trabalho aqueles que são julgados pertinentes para o ensino de leitura em um ambiente de não imersão, como é o caso do aprendizado de língua alemã no Brasil. Mesmo que haja similaridade entre a L1 e LA, as dificuldades de compreender um texto são de caráter linguístico e extralinguístico e ocorrem em diferentes níveis. É necessário que haja uma intervenção por parte do professor, propiciada, por exemplo, via instrução explícita de aspectos linguísticos, que mostre a eficácia da transformação do conhecimento de implícito a explícito, para acelerar o processo e permitir uma aprendizagem de leitura mais eficiente.

Estudos futuros decorrentes desta pesquisa poderiam replicar este trabalho com um número mais expressivo de participantes, para que talvez fosse possível confirmar de forma estatisticamente significativa os resultados parcialmente mostrados ou aqueles que não diferiram de forma significativa. Sugere-se também um estudo longitudinal, oportunizando um maior número de instruções explícitas e, inclusive, a aplicação de pós-teste imediato e pós-teste postergado podendo assim mensurar os efeitos de aprendizagem.

Outro ponto crucial da pesquisa é deixar explícita a relevância do papel do professor, 
pois, além de pensar em "como se ensina", espera-se que esteja interessado em saber "como se aprende", afinal conhecendo o aprendiz, que é o foco da aprendizagem, em suas necessidades, pode-se elaborar um ensino mais produtivo. Portanto, conhecer as dificuldades dos aprendizes, entender o porquê das suas ocorrências e saber quais medidas tomar para saná-las é de suma importância para que o professor possa auxiliar o aprendiz no processo rumo à consciência linguística e à leitura proficiente na língua adicional.

\section{Referências}

AEBERSOLD, J. A.; FIELD, M. L. From reader to reading teacher. New York: Cambridge University Press, 1997.

ANDERSON, N. J. Metacognitive Reading Strategy Awareness of ESL and EFL Learners. The CATESOL Journal, v. 16, n. 1, p. 11-27, 2004.

ALVES, U. K. O que é consciência fonológica. In: LAMPRECHT, R. R. et al. Consciência dos sons da língua: subsídios teóricos e práticos para alfabetizadores, fonoaudiólogos e professores de língua inglesa. Porto Alegre: EDIPUCRS, 2012a. p. 29-40.

ALVES, U. K. Consciência dos aspectos fonético-fonológico da L2. In: LAMPRECHT, R. R. et al. Consciência dos sons da língua: subsídios teóricos e práticos para alfabetizadores, fonoaudiólogos e professores de língua inglesa. Porto Alegre: EDIPUCRS, 2012b. p. 169-190.

ALVES, U. K. A explicitação dos aspectos fonético-fonológicos da L2: teoria e pesquisa na sala de aula. In: LAMPRECHT, R.R. et al. Consciência dos sons da língua: subsídios teóricos e práticos para alfabetizadores, fonoaudiólogos e professores de língua inglesa. Porto Alegre: EDIPUCRS, 2012c. p. 211-258.

BERNHARDT, E. B. Three Approaches to Reading Comprehension in Intermediate German. The Modern Language Journal, v. 67, n. 2, 1983, p. 111115. https://doi.org/10.1111/j.1540-4781.1983.tb01478.x

CAPOVILLA, A. G. S. Leitura, escrita e consciência fonológica: desenvolvimento intercorrelações e intervenções. 1999. 262f. Tese (Doutorado) - Instituto de Psicologia, Universidade de São Paulo, São Paulo, 1999.

CAPOVILLA, A. G. S.; GUTSCHOW, C. R. D.; CAPOVILLA, F. C. Habilidades cognitivas que predizem competência de leitura e escrita. Psicol. teor. prat., São Paulo, v. 6, n. 2, p. 13-26, dez. 2004.

CELCE-MURCIA, M. Teaching Pronunciation Communicatively. MEXTESOL Journal, v. 7, n. 1, p. 10-25, abr. 1983.

CELCE-MURCIA, M. Teaching Pronunciation: a course and reference guide. Cambridge: Cambridge University Press, 2010.

CELCE-MURCIA, M.; BRINTON, D. M.; GOODMAN, J. M. Teaching Pronunciation: a reference for teachers of English to speakers of other languages. Cambridge: Cambridge University Press, 1996. 
DUTRA, E. O. Os efeitos da instrução com foco na forma na aprendizagem de clíticos de $3^{\underline{a}}$ pessoas do espanhol por universitários brasileiros. 2015. Tese (Doutorado em Linguística Aplicada) - Universidade do Vale do Rio dos Sinos, São Leopoldo, RS, 2015.

EHLERS, S. Entwicklung von Lesekompetenz in der Fremdsprache. Babylonia 3+4, p. 31-38, 2006.

GOMBERT, J.E. Metalinguistic development. Hertfordshire: Harvester, Wheatsheaf, 1992.

GRABE, W. Current developments in second language reading research. TESOL. Quarterly, v. 25, n. 3, p. 375-406, 1991.

GRABE, W. Revisiting the MLA Report on reconfiguring foreign language programs: Therole of reading. Reading in a Foreign Language, v. 22, Suppl. 1, p. 11-14, Jan. 2010. https://doi.org/10.2307/3586977

HALE, A. D.; SKINNER, C. H.; WILLIAMS, J.; HAWKINS, R.; NEDDENRIEP, C. E.; DIZER, J. Comparing comprehension following silent and aloud reading across elementary and secondary students: Implication for curriculum-based measurement. The Behavior Analyst Today, v. 8, n. 1, p. 9-23, 2007. https://doi.org/10.1037/h0100101

JERÔNIMO, G. M. Fatores que impactam na proficiência em leitura em L2. Letrônica, v. 5, n. 3, p. 154-169, jul./dez. 2012.

LORANDI, A. From sensitivity to awareness: the morphological knowledge of Brazilian children between 2 and 11 years old and the representational redescription model. 2010. 200f. Tese (Doutorado) - Pontifícia Universidade Católica do Rio Grande do Sul, Porto Alegre, RS, 2011a.

LORANDI, A. A consciência linguística e o modelo de Redescrição Representacional: como explicar a discrepância entre os processos de consciência em diferentes microdomínios? In: FERREIRA-GONÇALVES, G.; BRUM DE PAULA, M. R.; KESKE-SOARES, M. (Orgs.) Estudos em Aquisição Fonológica. Pelotas: Editora e Gráfica UFPel, 2011b. p. 205-217.

LORANDI, A. KARMILOFF-SMITH A. From sensitivity to awareness: the morphological knowledge and the Representational Redescription Model. Letras de Hoje, Porto Alegre, v. 47, n. 1, jan./mar. 2012, p. 6-16.

LORANDI, A.; MARQUES, D. M. Subsídios teóricos e práticos para a elaboração de testes de consciência linguística. Revista Escrita, Rio de Janeiro, v. 21, p. 1-20, 2016. https://doi.org/10.17771/PUCRio.escrita.25993

KARMILLOF-SMITH, A. Beyond modularity: a developmental perspective on cognitive science. Cambridge, Mass: MIT Press, 1992.

KONRAD, J. T. Consciência fonológica, leitura e compreensão leitora em língua adicional: um estudo acerca da aprendizagem de alemão por falantes brasileiros. / Jordana Taís Konrad. São Leopoldo, 2018. 194 f. Dissertação (Mestrado) - Universidade do Vale do Rio dos SinosUNISINOS, São Leopoldo, RS, 2018.

KATO, M. O aprendizado da leitura. 5. ed. São Paulo: Martins Fontes, 1999.

KODA, K. Insights into Second Language Reading: A Cross-Linguistic Approach. Cambridge: Cambridge University Press, 2005. https://doi.org/10.1017/CBO9781139524841 
MOOJEN, S. Consciência fonológica: instrumento de avaliação sequencial. São Paulo: Casa do Psicólogo, 2011.

MORAIS, J. Criar leitores: para professores e educadores. São Paulo: Minha Editora, 2013.

MORAES, G. B. A aprendizagem do presente do subjuntivo do espanhol por alunos brasileiros: um estudo com foco na forma. 2014. 168f. Tese (Doutorado em Linguística) Universidade do Vale do Rio dos Sinos, São Leopoldo, RS, 2014.

NESDALE, A. R.; TUNMER, W. E. The development of metalinguistic awareness: a methodological overview. In: TUNMER, W. E.; PRATT, C.; HERRIMAN, M. L. (Ed.). Metalinguistic awareness in children: theory, research and implications. Berlim: SpringerVerlag, 1984, p. 36-55. https://doi.org/10.1007/978-3-642-69113-3 3

NORRIS, J. M.; ORTEGA, L. Effectiveness of L2 Instruction: A research synthesis and quantitative meta-analysis. Language Learning, v. 50, n.3, p. 417-528, 2000. https://doi.org/10.1111/0023-8333.00136

PEREIRA, L. Fatores compartilhados no processamento da leitura em L1 e L2. In: PEREIRA, V.W.; GUARESI, R. (Org.). Estudos sobre leitura: psicolinguística e interfaces. Porto Alegre: EDIPUCRS, 2012. p. 76-83.

PORFIRIO, L. Leitura em língua estrangeira: a importância do conhecimento prévio nas aulas de compreensão textual. BABEL: Revista Eletrônica de Línguas e Literaturas Estrangeiras, V. 4, n. 1, jan./jun. 2014.

SANTOS, A. A. A.; BORUCHOVITCH, E.; OLIVEIRA, K. CLOZE: um instrumento de diagnóstico e intervenção. São Paulo: Casa do Psicólogo, 2009.

SCHERER, A. P. R. Princípio alfabético e consciência fonológica: fatores determinantes no tempo de leitura de crianças em processo de alfabetização. Signo, Santa Cruz do Sul, v. 32, n. 53, p. 82-99, jul. 2007.

SCHMIDT, R. Attention. In: ROBINSON, P. (Ed.). Cognition and second language instruction. Cambridge: Cambridge University Press, 2001. p. 3-32. https://doi.org/10.1017/CBO9781139524780.003

SLOBIN, D. I. A Case Study of Early Language Awareness. In: SINCLAIR, A.; JARVELLA, R.J.; LEVELT, W. J. M. (Eds.). The Child's Conception of Language. Springer, Berlin, Heidelberg, 1980. (Springer Series in Language and Communication, 2).

SPADA, N. Form-Focussed Instruction and Second Language Acquisition: A Review of Classroom and Laboratory Research. Language Teaching, v. 30, p.73- 87, 1997. https://doi.org/10.1017/S0261444800012799

SPADA, N.; LIGHTBOWN, P. Form-Focused Instruction: Isolated or Integrated? Tesol Quarterly, v. 42, n. 2, p. 181-207, jun. 2008. https://doi.org/10.1002/j.15457249.2008.tb00115.x

SPADA, N.; TOMITA, Y. Interactions between type of instruction and type of language feature: a meta-analysis. Language Learning, v. 60, n. 2, p. 1-46, 2010. https://doi.org/10.1111/j.1467-9922.2010.00562.x

SWAIN, M. The Output Hypothesis and beyond: Mediating Acquisition through Collaborative Dialogue. In J. P. Lantolf (Ed.), Sociocultural Theory and Second Language Learning. Oxford: 
Oxford University Press, 2000, p. 97-114.

WOLFF, C. Descobrindo as rimas em poemas: estudo sobre os efeitos das rimas na consciência fonológica e suas relações com os demais níveis de consciência linguística durante o processo de alfabetização. 2015. 285f. Tese (Doutorado em Letras) - Pontifícia Universidade Católica do Rio Grande do Sul: Porto Alegre, 2015.

ZIMMER, M. O processamento da leitura em língua materna e em língua estrangeira: uma abordagem conexionista. Signo, Santa Cruz do Sul, p. 49-64, ago. 2008.

ZIMMER, M. A leitura em língua estrangeira e os efeitos da frequência e da consistência do insumo lexical em L2. Linguagem em (Dis)curso, Palhoça, SC, v. 10, n. 1, p. 111-131, jan./abr. 2010. https://doi.org/10.1590/S1518-76322010000100006 